\title{
Recovery of cobalt and nickel from spent lithium ion batteries with citric acid using leaching process: Kinetics study
}

\author{
Yuliusman $^{1, *}$, Silvia ${ }^{1}$, Annisaa Nurqomariah $^{1}$, and Radifan Fajaryanto ${ }^{1}$ \\ ${ }^{1}$ Chemical Engineering Department, Universitas Indonesia, Depok 16424, Indonesia
}

\begin{abstract}
Lithium ion batteries are commonly used as power sources for mobile phone, but by using it continually will degrade their capabilities. Battery replacements will cause a lot of waste in environment. Spent lithium ion batteries cathode contain heavy metals, such as cobalt and nickel. However it is also included as valuable metals thus recovery process is necessary. In this research, hydrometallurgical leaching process has been done for recovery of cobalt and nickel from spent lithium ion batteries using citric acid as a leaching agent by varying citric acid concentration $(0.5-1 \mathrm{M})$, reaction temperature $\left(50-80^{\circ} \mathrm{C}\right)$ and reaction time $(5-20$ minutes). The spent lithium ion batteries were analyzed by atomic absorption spectroscopy (AAS). The result showed that the leaching of lithium ion batteries using citric acid was depend on citric acid concentration, reaction temperature and reaction time. Based on kinetics study, the leaching reaction of cobalt and nickel from cathode powder using citric acid was chemically controlled process and the activation energy of cobalt and nickel were $67.12 \mathrm{~kJ} / \mathrm{mole}$ and $58.22 \mathrm{~kJ} / \mathrm{mole}$. The reaction order of leaching cobalt and nickel using citric acid was first-order reaction.
\end{abstract}

\section{Introduction}

Lithium ion batteries have been used as power source for mobile phones, laptops, electric vehicles and many electronic devices because of their long storage life, high specific energy, high energy density and rechargeable [1]. In 2020, the quantity and weight of lithium ion batteries can exceed 25 billion units and 500 thousand tons [2]. By using lithium ion batteries continually will degarde their capabilities and the replacement of battery is needed. Consequently, the increased of lithium ion batteries consumption can produced waste to the environment.

The compositions of lithium ion batteries are anode, cathode and electrolyte [3]. Lithium ion batteries consist of $5-20 \%$ cobalt, $5-10 \%$ nickel, $5-7 \%$ lithium, $15 \%$ organic chemicals, and $7 \%$ plastics, depend on the manufacturing process [4]. Cobalt and nickel metals in lithium ion batteries are heavy metals which can pollute the environment. On the other hand, this metals are valuable metals that useful in various fields. Therefore the recovery process is necessary to obtain this metals.

The common recycling processes to recover cobalt and nickel metals from spent lithium ion batteries are pyrometallurgy and hydrometallurgy. Compare to pyrometallurgy process, the hydrometallurgy process has several advantageous such as simple working, low energy consumption, low hazardous gases emission and high recovery rate [5]. The important step on hydrometallurgy process is leaching. Leaching is a method of solid-liquid extraction where the metals in the solid are dissolved using chemical solution (leaching agent). Commonly, leaching agent was used to dissolved metals from spent lithium ion batteries is acid solution. Many researchers are using inorganic acid as leaching agent such as sulfuric acid [4, 6], nitric acid [7] and hydrochloric acid [8]. This acid produce gas emission such as $\mathrm{Cl}_{2}, \mathrm{SO}_{3}$ dan $\mathrm{NO}_{\mathrm{x}}$ that can be harmful to the environtment and human health, as well as the waste that has been produced after the leaching process could contaminate the environment (soil and body of water) [9, 10]. Therefore the following research used organic acid as an alternative to substitute the usage of inorganic acid. Organic acid such as ascorbic acid [11], citric acid [12], L-tartaric acid [13] have been used as leaching agent to recover metals from spent lithium ion batteries and by using this organic acids, the leaching efficiency can be achived up to $99 \%$. The result of the research proved that organic acid can be used for metal recovery of spent lithium ion batteries.

Many researcher have been investigated the leaching kinetics study to determine the leaching reaction rate and the leaching mechanism $[14,15]$. Shrinking core model is usually used to evaluated the leaching reaction [16]. The application of this model is to explain situations which solid particles are being consumed by dissolution or reaction [17]. The kinetics models of leaching are residue layer diffusion control model [18] and surface chemical reaction control model [19]. In this research, leaching of cobalt and nickel from spent lithium ion batteries using citric acid solution as leaching agent was investigated by varying citric acid concentration,

Corresponding author: usman@,che.ui.ac.id 
reaction temperature and reaction time. The leaching kinetics were studied to determine the leaching kinetic model, the value of activation energy and the reaction order of leaching cobalt and nickel from spent lithium ion batteries.

\section{Experimental}

\subsection{Materials and reagents}

Spent lithium-ion batteries from mobile phone were collected from the local market. In this study, citric acid was used as a leaching agent and the solutions were prepared using distilled water.

\subsection{Dismantling and separation lithium ion batteries}

The spent lithium-ion batteries were soaked with $1 \mathrm{wt} . \%$ $\mathrm{NaCl}$ solution to discharged process. After discharging, the spent lithium-ion batteries were dismantled and then separated the components such as casing, anode and cathode. The cathode is taken and the black powder which attached to the aluminum foil was scraped using spatula and grounded to a fine powder. After the fine powder was formed, the powder was sieved to make a uniform particle size (100 mesh). The quantity of cobalt and nickel metals on the cathode powder were analyzed using AAS (Shimadzu AA-6300).

\subsection{Leaching of cathode powder}

All the leaching processes were carried out in $250 \mathrm{ml}$ pyrex glass reactor placed over hot plate with magnetic stirrer and equipped with a thermometer to control the temperature during leaching process, the reactor were closed to avoid the solution evaporated. Citric acid solution was poured into the reactor and allowed to reach thermal equilibrium. A known amount of cathode powder were poured into the reactor and stirred with magnetic stirrer with solid/liquid ratio $(20 \mathrm{~g} / \mathrm{L})$ and the stirring speed at $500 \mathrm{rpm}$. At different time intervals, the samples were taken and filtered using filter paper. After filtration, the sampels were analyzed using AAS (Shimadzu AA-6300) to detemine the content of cobalt and nickel metals. The citric acid concentration (0.5$1 \mathrm{M})$, reaction tem-perature $\left(50-80^{\circ} \mathrm{C}\right)$ and reaction time (5-20 minutes) were varied in this leaching process.

\section{Result and discussion}

\subsection{Effect of citric acid concentration}

The effect of citric acid concentration $(0.5 \mathrm{M}, 0.75 \mathrm{M}, 1$ $\mathrm{M})$ and reaction time (5 $\mathrm{min}, 10 \mathrm{~min}, 15 \mathrm{~min}, 20 \mathrm{~min})$ has been done with solid/liquid ratio $(20 \mathrm{~g} / \mathrm{L})$, reaction temperature $(80 \square)$ and a stirring speed $(500 \mathrm{rpm})$. This step has been done to determine the effect of citric acid concentration on leaching reaction of cathode powder.
Fig. 1 shows the effect of citric acid concentration on leaching cobalt and nickel at different reaction time. Based on Fig. 1 it can be shown that with the increasing of citric acid concentration and reaction time, the leaching efficiency also increase. The results obtained that $1 \mathrm{M}$ citric acid was the optimal leaching agent concentration with high percentage of leaching efficiency compared to the other concentrations.
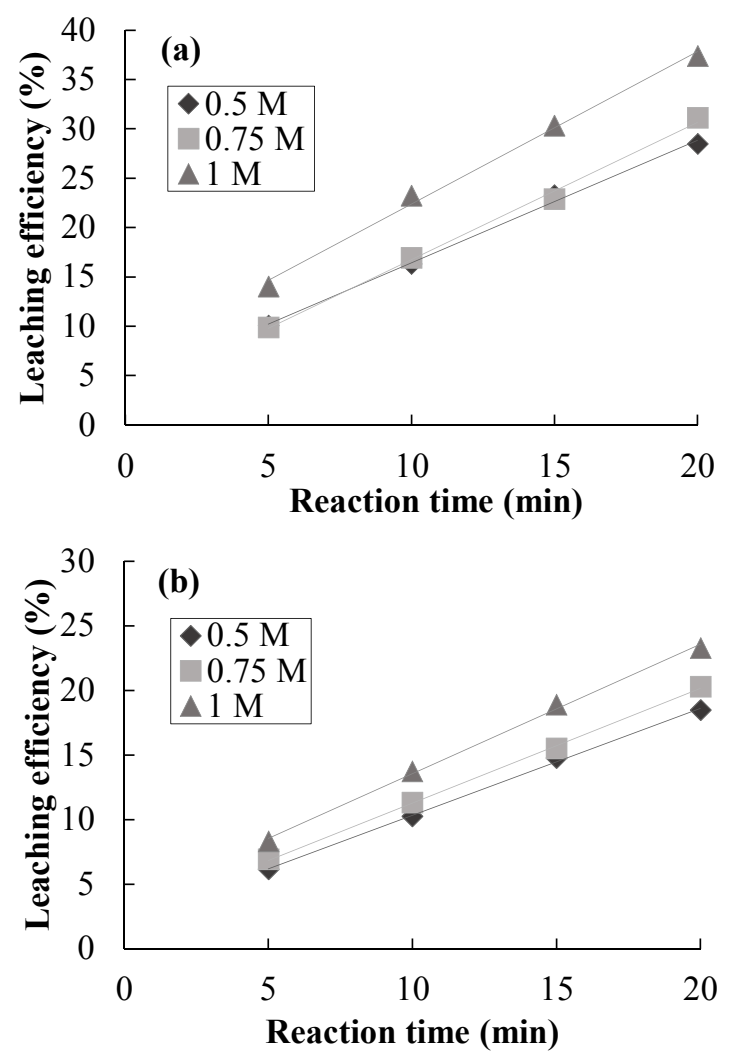

Fig. 1. Effect of citric acid concentration on leaching (a) cobalt and (b) nickel at different reaction time.

Citric acid is a weak organic acid. One molecule citric acid $\left(\mathrm{C}_{6} \mathrm{H}_{8} \mathrm{O}_{7}\right)$ consist of three carboxyl groups and when dissociated in water 1 mole of citric acid can produce 3 moles of $\mathrm{H}^{+}$ion although in fact not all $\mathrm{H}^{+}$ ions dissociate in the solution [20]. The dissociation reaction of citric acid in water shown in eq. (1-3) [20]:

$$
\begin{array}{ll}
\mathrm{H}_{3} \mathrm{Cit} \rightleftharpoons \mathrm{H}_{2} \mathrm{Cit}^{-}+\mathrm{H}^{+} & K_{a 1}=7.4 \times 10^{-4} \\
\mathrm{H}_{2} \mathrm{Cit}^{-} \rightleftharpoons \mathrm{HCit}^{2-}+H^{+} & K_{a 2}=1.7 \times 10^{-5} \\
\mathrm{HCit}^{2-} \rightleftharpoons \mathrm{Cit}^{3-}+\mathrm{H}^{+} & K_{a 3}=4.0 \times 10^{-7}
\end{array}
$$

\subsection{Effect of reaction temperature}

The effect of reaction temperature $\left(50^{\circ} \mathrm{C}, 60^{\circ} \mathrm{C}, 70^{\circ} \mathrm{C}\right.$, $80^{\circ} \mathrm{C}$ ) and reaction time (5 $\left.\mathrm{min}, 10 \mathrm{~min}, 15 \mathrm{~min}, 20 \mathrm{~min}\right)$ has been done with citric acid concentration is $1 \mathrm{M}$, solid/liquid ratio $(20 \mathrm{~g} / \mathrm{L})$ and a stirring speed $(500 \mathrm{rpm})$. This step is performed to determine the effect of reaction temperature on on leaching reaction of cathode powder. Fig. 2 shows the effect of reaction temperature on leaching cobalt and nickel at different reaction time. 
Based on Fig. 2, it can be seen that the leaching efficiency of $\mathrm{Co}$ and $\mathrm{Ni}$ metals were increased by increasing the reaction time. Higher reaction temperatures tend to increase the leaching efficiencies of metals [21]. The leaching reaction of the cathode powder is an endothermic or process so the leaching efficiencies of the metals will increase as temperature increased [22].
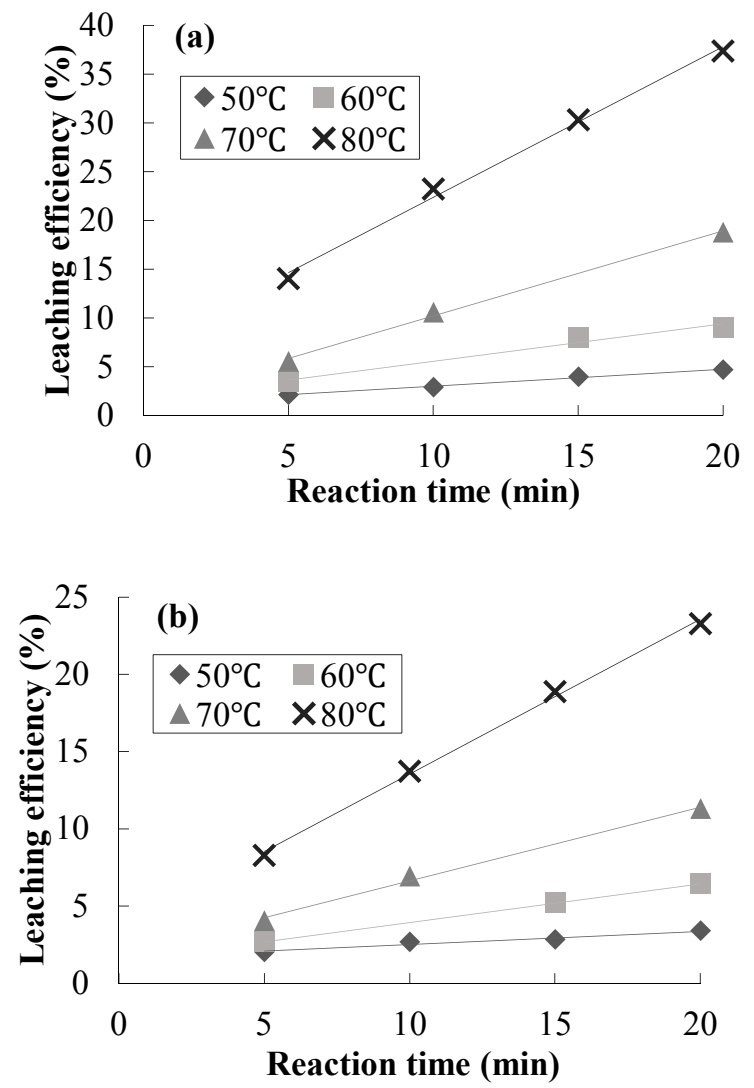

Fig. 2. Effect of reaction temperature on leaching (a) cobalt and (b) nickel at different reaction time.

\subsection{Kinetics study}

In kinetics study, the reactions that occur in the leaching process can be determined using shrinking core model. The shrinking core model used to describe a situation which solid particle will be consumed by dissolution process or reaction so the amount of consumed material will decrease [17]. The leaching reaction is divided into five steps [16]:

1. The citric acid molecule (leaching agent) diffuses through the bulk solution to the liquid-liquid interface.

2. This molecule diffuses through the diffusion layer to the unreacted core surface.

3. The citric acid molecules reach solid-liquid interface and reacts with solid core components and then metal ions dissolved and released to the solution.

4. The metal ion as the product will diffuse through the diffusion layer to the liquid-liquid interface.

5. The product diffuses into bulk solution.
Since leaching is a heterogeneous reaction and it occurs on the outer surface of the unreacted particle, therefore the rate of leaching reaction can be controlled by chemical reactions on the material surface or diffusion control model [18]. In solid-liquid reaction, the reaction rate is usually controlled by diffusion through the product layer or by chemical reaction on the surface of the material. If the reaction was controlled by diffusion through product layer, the reaction rate equation was [23]:

$$
1-\frac{2}{3} X-(1-X)^{\frac{2}{3}}=k_{d} t
$$

If the reaction was chemically controlled at the surface, the reaction rate equation was [23]:

$$
1-(1-X)^{\frac{1}{3}}=k_{c} t
$$

Where $\mathrm{X}$ is metal fraction, $k_{d}$ is the diffusion rate constant, $k_{c}$ adalah is the chemical surface reaction rate constant and $\mathrm{t}$ is the reaction time ( $\mathrm{min})$. To determine the appropriate kinetic model for leaching reaction, the metal fraction which obtained on the effect of reaction temperature was used into the reaction rate equations for each kinetic model. Fig. 3 shows the plot of $1-(1-X)^{1 / 3}$ vs $t$ and $1-2 / 3 X-(1-X)^{2 / 3}$ vs $t$ of cobalt and nickel. Based on Fig. 3, the average value of the correlation coefficients $\left(\mathrm{R}^{2}\right)$ was 0.99 , so the leaching reactions for $\mathrm{Co}$ and $\mathrm{Ni}$ metals were chemically controlled at the surface. This indicated the leaching reaction for $\mathrm{Co}$ and $\mathrm{Ni}$ metals follow the surface chemical reaction control model. This result was consistent with research $\mathrm{Li}$ et al. (2018) by using citric acid as leaching agent and hydrogen peroxide, the result showed that the leaching of Co and $\mathrm{Ni}$ from spent lithium ion batteries were the surface chemical reaction control model [16]. The leaching of $\mathrm{Zn}$ from $\mathrm{Zn}-\mathrm{Mn}$ spent batteries using citric acid was also follow the surface chemical reaction control model [24]. Table 1 shows the $k_{c}$ value at different reaction temperature using the surface chemical reaction control model. The $k_{c}$ value (the chemical surface reaction rate constant) can be used to calculated the activation energy of $\mathrm{Co}$ and $\mathrm{Ni}$.

Table 1. $k_{c}$ value at different reaction temperature using the surface chemical reaction control model

\begin{tabular}{ccc}
\hline Metal & Temperature $\left({ }^{\circ} \mathrm{C}\right)$ & $\boldsymbol{k}_{\boldsymbol{c}}\left(\mathbf{m i n}^{-\mathbf{1}}\right)$ \\
\hline $\mathrm{Co}$ & 50 & 0.0009 \\
& 60 & 0.0017 \\
& 70 & 0.0034 \\
& 80 & 0.0076 \\
\hline $\mathrm{Ni}$ & 50 & 0.0007 \\
& 60 & 0.0011 \\
& 70 & 0.0021 \\
& 80 & 0.0044 \\
\hline
\end{tabular}



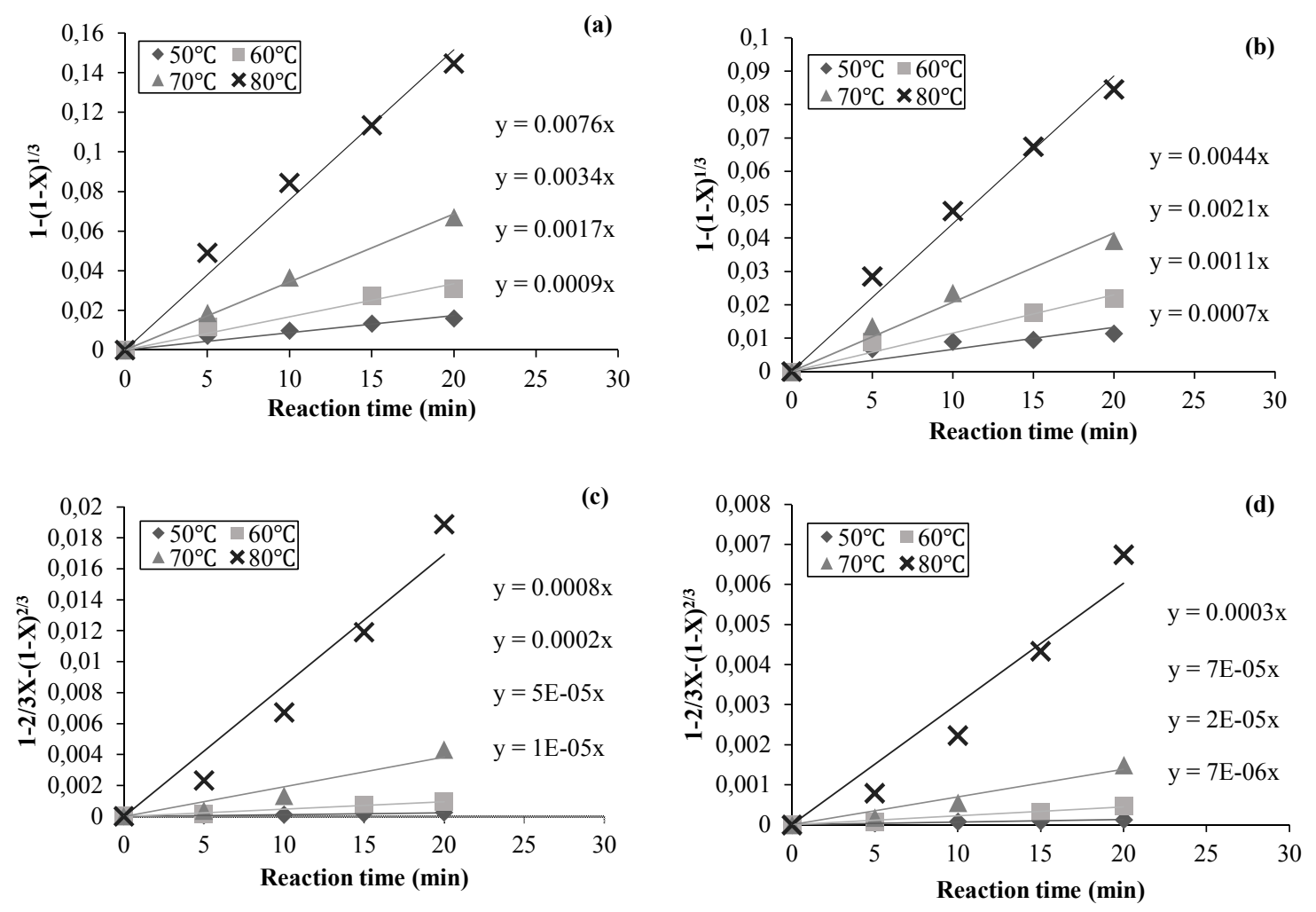

Fig. 3. Plot of $1-(1-X)^{1 / 3}$ vs t (a) cobalt (b) nickel and $1-\frac{2}{3} X-(1-X)^{2 / 3}$ vs t (c) cobalt and (d) nickel.

\subsection{Calculation of activation energy}

The results of kinetics studies based on reaction temperature can be used to calculate the activation energy of $\mathrm{Co}$ and $\mathrm{Ni}$ metals by using the Arrhenius equation shown in eq. (6) [25]:

$$
k=A e^{-\frac{E a}{R T}}
$$

Where $\mathrm{A}$ is pre-exponential factor $(1 / \mathrm{min}), \mathrm{E}_{\mathrm{a}}$ is activation energy $(\mathrm{J} / \mathrm{mole}), \mathrm{R}$ is universal gas constant $(\mathrm{J} /$ mole. $\mathrm{K})$ and $\mathrm{T}$ is temperature $(\mathrm{K})$. To find out the activation energy of $\mathrm{Co}$ and $\mathrm{Ni}$ metals, the $\mathrm{k}$ value obtained from the surface chemical reaction control model is used to make Arrhenius plot. Fig. 4 shows the Arrhenius plot of leaching cobalt and nickel metals (plot of $\ln \mathrm{k}$ with $1 / \mathrm{T}$ ). Based on the linear regression in Fig. 4 , it shows the value of activation energy for $\mathrm{Co}$ and $\mathrm{Ni}$ metals. The slope is the value of $-\frac{E_{a}}{R}$. Table 2 shows the activation energy value using the surface chemical reaction control model.

Table 2. Activation energy value using the surface chemical reaction control model

\begin{tabular}{cccc}
\hline Metal & Slope & $\mathbf{E}_{\mathbf{a}}(\mathbf{k J} / \mathbf{m o l e})$ & $\mathbf{R}^{2}$ \\
\hline $\mathrm{Co}$ & -8.0726 & 67.12 & 0.9936 \\
$\mathrm{Ni}$ & -7.0021 & 58.22 & 0.9828 \\
\hline
\end{tabular}

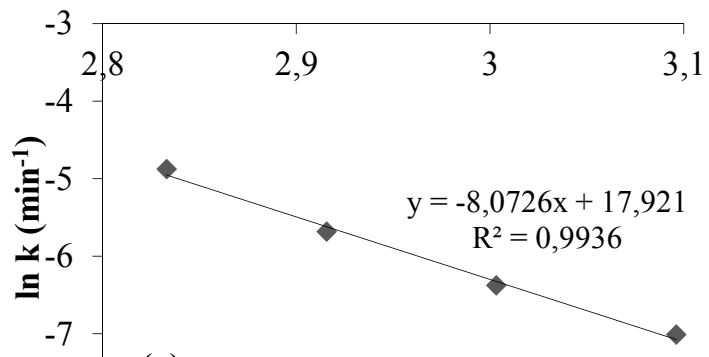

(a)

$1 / \mathrm{T} \times 10^{3}\left(\mathrm{~K}^{-1}\right)$

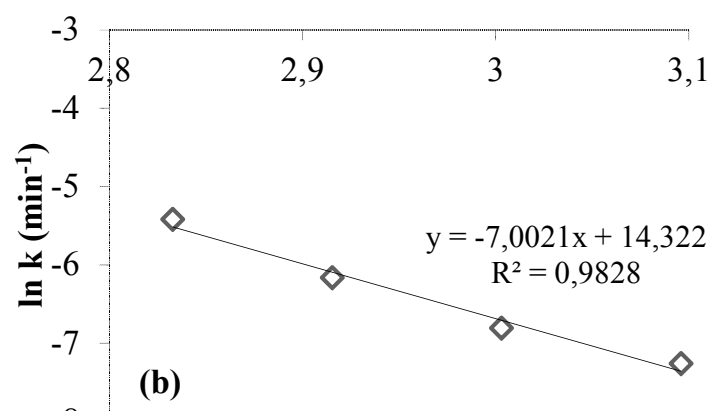

$1 / \mathrm{T} \times 10^{3}\left(\mathrm{~K}^{-1}\right)$

Fig. 4. Arrhenius plot of leaching (a) cobalt and (b) nickel. 
The value of activation energy for Co was 67.12 $\mathrm{kJ} /$ mole and the activation energy value for $\mathrm{Ni}$ was 58.22 $\mathrm{kJ} / \mathrm{mole}$. The value of the activation energy for these two metals were greater than $40 \mathrm{~kJ} / \mathrm{mole}$, which indicating that the leaching reaction was chemically controlled at the surface [26]. The activation energy for diffusion through the product layer is usually under $21 \mathrm{~kJ} / \mathrm{mole}$ and if the reaction is chemically controlled at the surface, the activation energy is $40-100 \mathrm{~kJ} /$ mole $[19,27]$.

\subsection{Determination of reaction order}

In order to determine the reaction order of leaching reaction, the $\mathrm{X}$ value from the effect of citric acid concentration was applied to the reaction rate equation. If the reaction is first order, the reaction rate equation is [28]:

$$
-\ln (1-X)=k t
$$

If the reaction is second order, the reaction rate equation is [29]:

$$
[1 /(1-X)]-1=k t
$$

Where $\mathrm{X}$ is metal fraction, $k$ is the rate constant and $\mathrm{t}$ is the reaction time (min). Fig. 5 shows the plot of $-\ln (1-X)$ vs $t$ and Fig 6 shows the plot of $[1 /(1-X)]-1$ vs t. Fig. 5 and Fig. 6 were constructed to determine the reaction order of leaching cobalt and nickel.
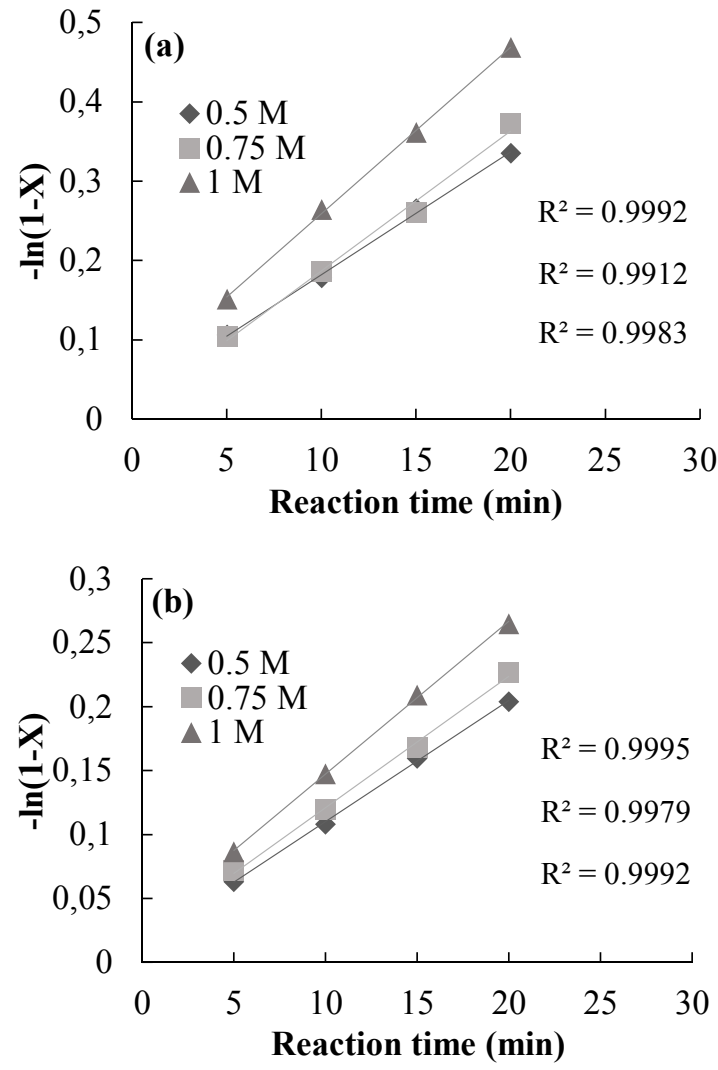

Fig. 5. Plot of $-\ln (1-X)$ vs t (a) cobalt and (b) nickel.

According to Fig. 5 and Fig. 6, a good linear relationship were presented on both figure. Fig. 5 shows the correlation coefficients $\left(\mathrm{R}^{2}\right)$ both metals are higher than 0.99 so the reaction order of leaching cobalt and nickel is first-order reaction. Which means that the rate of leaching reaction is directly proportional to the concentration of reactant.
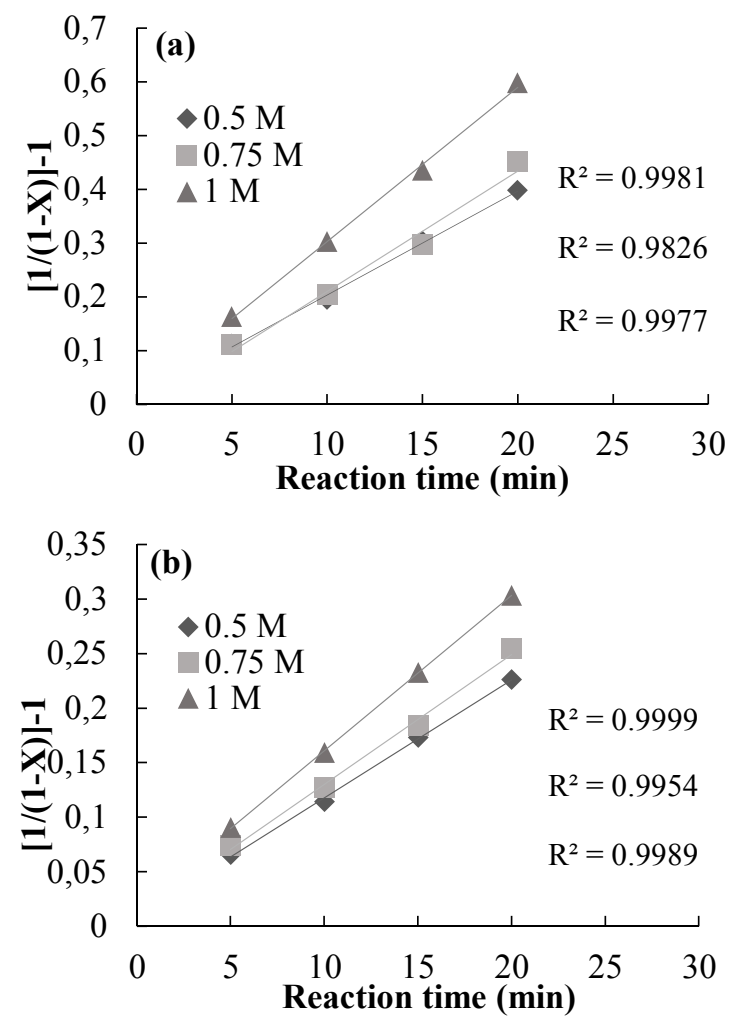

Fig. 6. Plot of $\left[\frac{1}{1-X}\right]-1$ vs $t$ (a) cobalt and (b) nickel.

\section{Conclusion}

Based on the experiment result, the leaching efficiency increased with the increased of citric acid concentration, reaction temperature and reaction time. Based on kinetics study, the leaching reaction of cobalt and nickel from cathode powder using citric acid follow surface chemical reaction control model with the activation energy of cobalt and nickel are $67.12 \mathrm{~kJ} /$ mole and 58.22 $\mathrm{kJ} /$ mole. The result shows that reaction order of cobalt and nickel are first-order reaction.

This research was supported by "Hibah Publikasi Internasional Terindeks untuk Tugas Akhir Mahasiswa UI (PITTA)" 2018 from Universitas Indonesia

\section{References}

1. N. Armaroli and V. Balzani, Energy Environ. Sci. 4, 3193-3222 (2011)

2. X. Zeng, J. Li, N. Singh, Crit. Rev. Environ. Sci. Technol. 44, 1129-1165 (2014)

3. H. Hollmark, Redox reactions in li-ion battery cycling and in $\mathrm{Cu}$ corrosion studied by soft $x$-ray spectroscopy (Uppsala University, Sweden, 2011)

4. J. Kang, G. Senanayake, J. Sohn, S.M. Shin, Hydrometallurgy 100, 168-171 (2010) 
5. Q. Meng, Y. Zhang, P. Dong, Waste Manage. 64, 214-218 (2017)

6. L. Chen, X. Tang, Y. Zhang, L. Li, Z. Zeng, Y. Zhang, Hydrometallurgy 108, 80-86 (2011)

7. C.K. Lee and K.I. Rhee, Hydrometallurgy 68, 5-10 (2003)

8. M.A.H. Shuva, A.S.W. Kurny, J. Inst. Eng. India Ser. D 94, 13-16 (2013)

9. Y. Weng, S. Xu, G. Huang, C. Jiang, J. Hazard. Mater 246, 163-172 (2013)

10. Y. Zheng, H.L. Long, L. Zhou, Z.S. Wu, X. Zhou, L. You, J.W. Liu, Int. J. Environ. Res. 10, 159-168 (2016)

11. L. Li, J. Lu, Y. Ren, X.X. Zhang, R.J. Chen, F. Wu, K. Amine, J. Power Sources 218, 21-27 (2012)

12. X. Chen and T. Zhou, Waste Manage. Res. 32, 1083- 1093 (2014)

13. L.P. He, S.Y. Sun, Y.Y. Mu, X.F. Song, J.G. Yu, ACS Sustain. Chem. Eng. 5, 714-721 (2016)

14. C.K. Lee and K.I. Rhee, Hydrometallurgy 68, 5-10 (2003)

15. M.A.H. Shuva and A.S.W. Kurny, J. Inst. Eng. India Ser. D 94, 13-16 (2013)

16. L. Li, Y. Bian, X. Zhang, Y. Guan, E. Fan, F. Wu, R. Chen, Waste Manage. 71, 362-371 (2018)

17. H.S. Fogler, Element of chemical reaction engineering (Prentice Hall PTR, New Jersey, 1999)

18. H.L. Hoşgün, H. Kurama, Ind. Eng. Chem. Res. 51, 1087-1092 (2012)
19. E.A. Abdel-Aal, Hydrometallurgy 55, 247-254 (2000)

20. L. Li, J. Ge, F. Wu, R. Chen, S. Chen, B. Wu, J. Hazard. Mater. 176, 288-293 (2010)

21. M.P. Kamble and G.D. Yadav, Ind. Eng. Chem. Res. 56, 1750-1757 (2017)

22. B. Fan, X. Chen, T. Zhou, J. Zhang, B. Xu, Waste Manage. Res. 34, 474-481 (2016)

23. P. Meshram, B.D. Pandey, T.R. Mankhand, Waste Manage. 51, 196-203 (2016)

24. Yuliusman, R.A. Amiliana, P.T. Wulandari, M. Huda, F.A. Kusumadewi, IOP Conf. Ser. Mater. Sci. Eng. 333, 012037 (2018)

25. M.K. Jha, A. Kumari, A.K. Jha, V. Kumar, J. Hait, B.D. Pandey, Waste Manage. 33, 1890-1897 (2013)

26. J.C. Rendón-Angeles, Z. Matamoros-Veloza, A. Matamoros Veloza, R. Perez-Garibay, J.L. Rodriguez-Galicia, Y. Kazumichi, Ind. Eng. Chem. Res. 56, 9942-9952 (2017)

27. M. Ashraf, Z.I. Zafar, T.M. Ansari. Hydrometallurgy 80, 286-292 (2005)

28. W. E. Brown, D. Dollimore, A.K. Galwey, Reactions in the solid state, in: C.H. Bamford, C.F.H Tipper (Eds) Comprehensive chemical kinetics (Elsevier, Amsterdam, 1980)

29. A. Khawam and D.R. Flanagan, J. Phys. Chem. B 110, 17315-17328 (2006) 